\title{
MORPHOLOGICAL HAIR IDENTIFICATION KEY OF COMMON MAMMALS IN TURKEY
}

\author{
SARI, A.* - ARPACIK, A. \\ Department of Wildlife Ecology and Management, Faculty of Forestry, Karadeniz Technical \\ University, 61080 Trabzon, Turkey \\ *Corresponding author \\ e-mail: alptugsari@ktu.edu.tr; phone:+90-535-639-7001; fax: +90-462-325-7499 \\ (Received $25^{\text {th }}$ May 2018; accepted $5^{\text {th }}$ Jul 2018)
}

\begin{abstract}
The aim of this study was to research the morphology and to make ready a hair identification key for common mammals in Turkey and also to make up a comprehensive method for the preparation of hair identification key for Turkey's mammals. Despite the wide application of this technique in the determination of diet composition in large carnivores, it has not been used in Turkey up to this point, thus this paper is the first study and an appropriate guide for using this technique in ecological studies and management of many species and populations in Turkey. In this research, hair structures of eighteen species representing four mammalian orders including Artiodactyla such as wild goat, chamois, red deer; Carnivora such as leopard, eurasian lynx, gray wolf, brown bear; Lagomorpha and Rodentia were investigated. The studied large carnivore species constitute the main predator species and the others are important prey sources. The microscopic structure of the hair was studied using the hair medulla and cuticle scale patterns. Afterwards, the structural features of hair for each species were comparatively used in order to prepare a descriptive and photographic hair identification key.
\end{abstract}

Keywords: microscopic structure, photographic key, medulla, cuticle, wildlife

\section{Introduction}

Hair identification of mammalian species has efficient practices in wildlife, biology, ecology and forensic medicine in particular the study of food habits of carnivores using investigation of prey hair in scats is widely utilized. The purpose of morphological identification of animal hairs is to classify the animal species from an unknown hair pattern to a special taxon based on well-defined, genetically based features (Tridicio et al., 2014). Knowledge of diet of carnivores is an important and essential factor for management and conservation of endangered species (Klare et al., 2011). Several techniques have been suggested to study species diet (Karanth and Sunquist, 1995; Ciucci et al., 1996). Despite these methods, scat analysis has been extensively used because this method is a non-harmful way and scat collections can be easily done throughout the year (Boitani and Powell, 2012). Various hair identification key atlases have been published on European mammal hairs (Day, 1966; Dziurdzik, 1978; Keller, 1978; Faliu et al., 1980; Debrot et al., 1982; Teerink, 1991; Meyer et al., 2002; Cornally and Lawton, 2016). Dietary habits of species are critical for the study of sustainable wildlife conservation and management (Treves and Karanth, 2003). Knowing the answer of question "Who eats what?" is essential for recognizing predator-prey relationships and a healthy ecosystem (Symondson, 2002; Sheppard and Harwood, 2005). Diet is basic principle in animal ecology but is specifically critical in the study of large carnivore species (Gese, 2001; Treves and Karanth, 2003). Scat analysis method is the most widely used to examine carnivore diet preferences (Leopold and Krausman, 1986; Gamberg and Atkinson, 1988). Knowledge of predators' diet is very important 
for sustainable wildlife conservation and management (Anwar et al., 2012). Scat analysis is based on morphological identification of indigestible prey remains such as bone and hair (Symondson, 2002; Sheppard and Harwood, 2005). Carnivore food habits studies from the prey hairs in scats has been widely accepted and used for describing the diet of mammalian predators, because of non-destructiveness of hairs and easily available scats at all times (De-Marinis and Asprea, 2005). The research of hair has been used in wildlife study in order to gather information such as species distribution, population density, species' dietary habits and translocation studies (Waters and Lawton, 2011).

Guard hairs have the ability to be used for identification, as a result, in this study only guard hairs were used to prepare the identification key. Hair structure is made of three layers: the medulla, the cortex and an outermost layer, the cuticle (Oli, 1993). The cortex is the middle layer of hair. It is composed of longitudinal and shriveled cells, which appears under the light microscope as a homogeneous mass without any details. This layer is of limited value for identification (Teerink, 1991). The medulla is composed shriveled dead cells but unlike the cortex they are clearly visible (Teerink, 1991; Hausman, 1920). Hair scale patterns formed by the cuticle and hair crosssectional patterns formed by the cortex and medulla are the two main characteristics used in species recognition (Moyo, 2005). In identifying hair species it is necessary to compare the scales and medulla from the same parts of the hairs (Hausman, 1920).

The use of hair identification key could be helpful to distinguish hair structures of many related and unrelated species. Methods of direct comparison by microscopy have also been used but they are all time consuming (Oli, 1993). Photographic reference key has been proved the best and easy method for the comparison of characteristics of hairs recovered from the scats of carnivores (Oli, 1993).

In this study, a photographic hair identification key of common mammals of Turkey was developed. In this paper, hair structures of eighteen mammalian species have been investigated. This study is also important for all wildlife studies as important for Turkey. The aim of this study is to present a descriptive and photographic identification key and to provide a descriptive and simple method for the preparation of hair identification keys for other mammals in future studies.

\section{Materials and methods}

The structure of guard hair was examined in eighteen different mammal species found throughout Turkey. We investigated the hair structures of eighteen species representing four mammalian orders and nine families including Bovidae, Cervidae, Suidae, Canidae, Felidae, Mustelidae, Ursidae, Leporidae, and Sciuridae (Table 1). We collected hair tufts from taxidermied animals housed in Karadeniz Technical University, Wildlife Museum of Department of Wildlife Ecology and Management. All of the samples were dorsal guard hair from mature adult animals. Guard hairs are important in species identification as they exhibit diagnostically reliable features (Eunok et al., 2014). The hair samples were collected from at least five spots in the dorsolateral body region of each specimen (Wallis, 1993). The hairs samples were taken from the dorsal region of the body. De Marinis and Asprea (2005) noted that hairs from other body regions show similar characteristics to dorsal hair, but are often less distinct making identification more problematic. 
Table 1. Studied mammal species in this research

\begin{tabular}{|c|c|c|c|}
\hline Order & Family & Scientific Name & English Name \\
\hline \multirow{3}{*}{ Artiodactyla } & Bovidae & $\begin{array}{c}\text { Capra aegagrus } \\
\text { Gazella subgutturosa } \\
\text { Rupicapra rupicapra }\end{array}$ & $\begin{array}{c}\text { Wild goat } \\
\text { Goitered gazelle } \\
\text { Chamois }\end{array}$ \\
\hline & Cervidae & $\begin{array}{c}\text { Capreolus capreolus } \\
\text { Cervus elaphus } \\
\text { Dama dama }\end{array}$ & $\begin{array}{c}\text { Roe deer } \\
\text { Red deer } \\
\text { Fallow deer }\end{array}$ \\
\hline & Suidae & Sus scrofa & Wild boar \\
\hline \multirow{4}{*}{ Carnivora } & Canidae & $\begin{array}{l}\text { Canis aureus } \\
\text { Canis lupus } \\
\text { Vulpes vulpes }\end{array}$ & $\begin{array}{c}\text { Golden jackal } \\
\text { Gray wolf } \\
\text { Red fox } \\
\end{array}$ \\
\hline & Felidae & $\begin{array}{c}\text { Lynx lynx } \\
\text { Panthera pardus }\end{array}$ & $\begin{array}{c}\text { Eurasian lynx } \\
\text { Leopard }\end{array}$ \\
\hline & Mustelidae & $\begin{array}{c}\text { Martes foina } \\
\text { Meles meles } \\
\text { Lutra lutra }\end{array}$ & $\begin{array}{c}\text { Stone marten } \\
\text { European badger } \\
\text { European otter }\end{array}$ \\
\hline & Ursidae & Ursus arctos & Brown bear \\
\hline Lagomorpha & Leporidae & Lepus europaeus & European hare \\
\hline Rodentia & Sciuridae & Sciurus anomalus & Caucasian squirrel \\
\hline
\end{tabular}

\section{Medulla structure}

Dead cell and the gaps between them create several patterns of medulla that are good indicators for identification (Teerink, 1991). If hair samples are not prepared for observation under light microscope, in most cases, medulla seems so dark that its structure can hardly be observed. Accordingly, the hair is placed into the mixture solution of $70 \%$ hydrogen peroxide and $30 \%$ ammonia for about 20 to 60 minutes so that hair colour is washed and the hair becomes transparent (De Marinis and Agnelli, 1993; Rezaie et al., 2012). Then, samples were placed in the water to be thoroughly washed and then a number of samples were placed on gelatine-treated solution and some were placed on liquid paraffin. Comparison between paraffin and gelatine slide displayed a more precise structure of the medulla (Teerink, 1991). Hair samples impregnated with paraffin and gelatine were placed on slides. Then, these slides were studied under a light microscope with a magnification of 100 and 400 .

In this study, we have used the hair classification system that was proposed by De Marinis and Asprea (2005) and Teerink (1991). This classification has been based on cellular composition, cellular structure and pattern, medulla margins and width of cortex (Teerink, 1991) (Fig. 1).

\section{Cuticle scales pattern}

The outermost layer, the cuticle, is made up of a large number of overlapping transparent scales of keratin. Observation placement of scales pattern is usually impossible or can hardly be seen with a light microscope without special preparation (Teerink, 1991; Rezaie et al., 2012). Therefore, it is essential to make a gelatine impression of the hair or to use an electronic microscope (Homan and Genoways, 
1978). Although the electronic microscope showed more detail of cuticular scale pattern, gelatine impressions were more practical (Perrin and Campbell, 1980). For this reason, the mixture of gelatine solution was placed on a slide, consequently hairs were placed on it. After drying for about 20 to 40 minutes, the gelatine will be solid and the hairs can be removed. As a consequence, the scales of hairs remaining on the gelatine can be seen under the light microscope with a magnification of 100 and 400 (Teerink, 1991; Oli, 1993). In this study, scale patterns of hairs are classified according to longitudinal axis of the hair, the structure of scale margins and the distance between scale margins (Teerink, 1991) (Fig. 1).
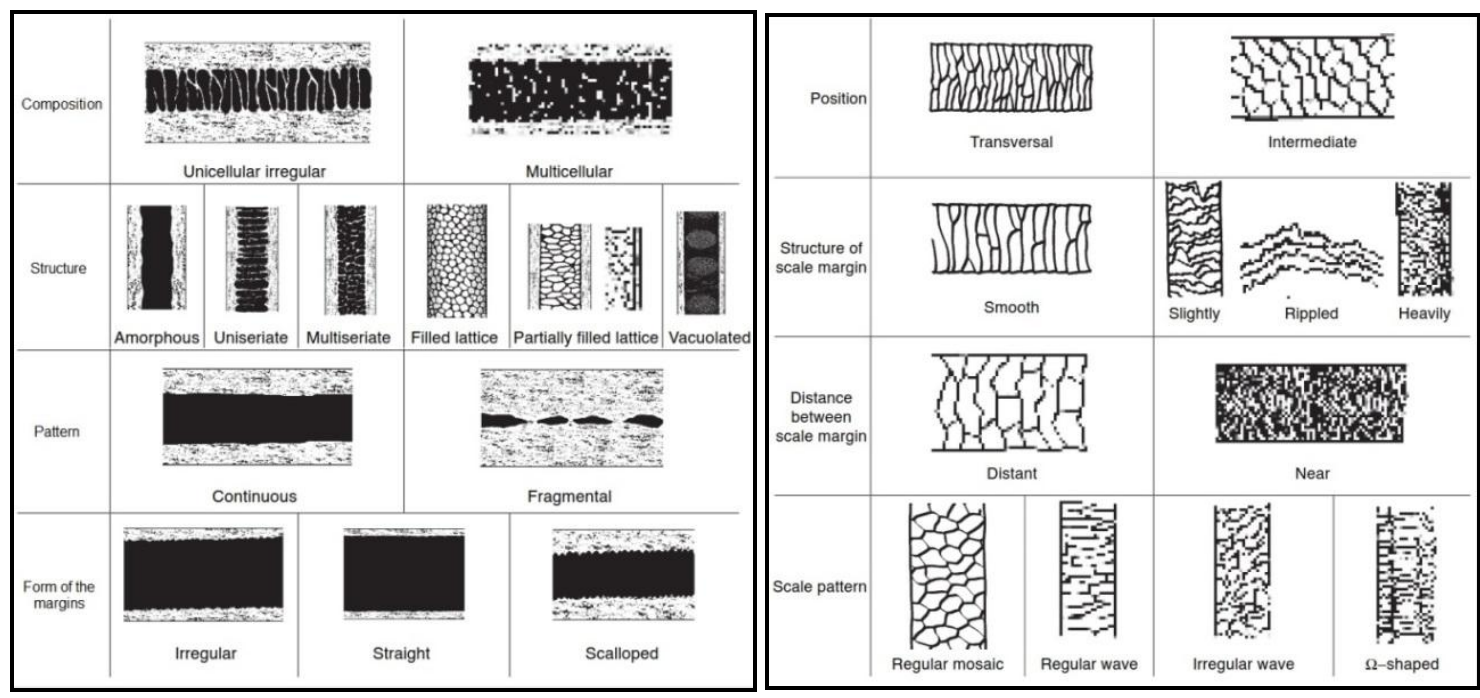

Figure 1. Medulla (left) and Cuticle (right) classification system used in our hair key to identify common mammals of Turkey (Teerink, 1991)

\section{Results and discussion}

In all species, the medulla structure of the hairs is an important key for the identification of species at the family level and the medulla structure per species is constant throughout the hair length (Homan and Genoways, 1978; Toth, 2002; De Marinis and Asprea, 2005). But at lower levels, such as subfamily and genus, for instance the wild goat and goitered gazelle, the medulla structure does not give the correct results in species identification, due to its high resemblance, so the cuticle pattern was used for identification of both species. The cuticle pattern shows more changes in hair length at family and subfamily levels. The cuticle is a useful tool used to distinguish species among wild ungulates. (De Marinis and Asprea, 2005). Therefore, firstly, in an attempt for microscopic identification, we investigated the medulla structure up to order and family levels and in order to identify at genus and species levels, it is recommended to use the cuticle pattern. As a result, in microscopic morphology the use of medulla structure has priority over the cuticle pattern and the use of the cuticle pattern individually, will cause confusion (De Marinis and Agnelli, 1993).

Keller (1981) separated Cervidae, which have similar medulla structure, from Bovidae on the basis of cross-sections. But hair cross-sectioning is a sophisticated and time consuming process in laboratory. So, we distinguished these taxa by the cuticle of hairs without cross-sectioning. The methods applied in this research can be easily, quickly and economically used in wildlife researches like previous studies (Toth, 2002; 
Chernova, 2003; Eunok et al., 2014). For a wildlife researcher who knows the worked habitat well, these simply obtainable data are very important resources at identifying for species.

Among all studied mammals species, european badger, wild boar and brown bear hairs can be identified without the help of microscopic studies. The hairs of these species can be easily identified by the naked eye based on the general view of the hair, which are hard and thick. However, they have bristly hairs which can be distinguished from those of other species even if the researcher is not highly skilled in hair identification (De Marinis and Asprea, 2005). Medulla and cuticle features of these species are not clearly displayed due to amorphous cellular structure and morphological structures of their hairs. The hair of those animals should be classified by macroscopic view for hair profile and hair general appearance (Eunok et al., 2014).

\section{Medulla features}

All investigated Leporidae, Sciuridae family and wild ungulates, except wild boar, showed a multicellular composition. The predator mammals studied, except european badger and brown bear, showed an unicellular composition. European badger and brown bear showed a multicellular composition. The reason of differences medulla composition of these species is their hair structures which have amorphous cellular structure. All studied mammal species' medullary features are listed in Table 2.

Table 2. Medullary features of 18 mammal species from Turkey

\begin{tabular}{l|c|c|c|c|c}
\hline \multicolumn{1}{c|}{ Species } & Composition & Structure & Pattern & $\begin{array}{c}\text { Form of the } \\
\text { margin }\end{array}$ & $\begin{array}{c}\text { Cortex } \\
\text { width }\end{array}$ \\
\hline Capra aegagrus & Multicellular & Partially filled lattice & Continuous & Scalloped & Narrow \\
Gazella subgutturosa & Multicellular & Partially filled lattice & Continuous & Scalloped & Narrow \\
Rupicapra rupicapra & Multicellular & Partially filled lattice & Continuous & Scalloped & Narrow \\
Capreolus capreolus & Multicellular & Partially filled lattice & Continuous & Scalloped & Narrow \\
Cervus elaphus & Multicellular & Partially filled lattice & Continuous & Scalloped & Narrow \\
Dama dama & Multicellular & Partially filled lattice & Continuous & Scalloped & Narrow \\
Sus scrofa & Multicellular & Amorphous & Continuous & Irregular & Width \\
Canis aureus & Unicellular & Vacuolated & Continuous & Irregular & Medium \\
Canis lupus & Unicellular & Vacuolated & Continuous & Irregular & Medium \\
Vulpes vulpes & Unicellular & Multiseriate & Continuous & Irregular & Medium \\
Lynx lynx & Unicellular & Uniseriate & Continuous & Scalloped & Medium \\
Panthera pardus & Unicellular & Uniseriate & Continuous & Scalloped & Medium \\
Martes foina & Unicellular & Uniseriate & Continuous & Scalloped & Medium \\
Meles meles & Multicellular & Amorphous & Continuous & Irregular & Medium \\
Lutra lutra & Unicellular & Uniseriate & Continuous & Scalloped & Medium \\
Ursus arctos & Multicellular & Amorphous & Continuous & Straight & Width \\
Lepus europaeus & Multicellular & Multiseriate & Continuous & Scalloped & Narrow \\
Sciurus anomalus & Unicellular & Uniseriate & Continuous & Scalloped & Medium \\
\hline
\end{tabular}

Studied Bovidae and Cervidae family species have a partially filled lattice hair structure. Canidae family species except red fox have vacuolated hair structure. Red fox has multiseriate hair structure. Felidae family species have uniseriate hair structure. 
European hare has multiseriate hair structure. Mustelidae family species except european badger have uniseriate hair structure. European badger has amorphous hair structure. Caucasian squirrel has uniseriate hair structure. Faliu et al. (1980) and Keller (1981) found the medullary lattice structure in wild boar. But, we found the medullary amorphous hair structure in wild boar and brown bear. We did not find in brown bear, as previously reported by Debelica and Thies (2009) found the medullary hair structure vacuolated in brown bear. All investigated mammals, showed a continous pattern. Studied Bovidae, Cervidae, Felidae, Leporidae, Mustelidae (except european badger) and Scirudae family species have form of the scalloped hair margin. Canidae family species, european badger and wild boar have form of the irregular hair margin.

\section{Cuticle features}

Among the mammals studied, except the leopard, position is transverse. The leopard has the most diverse pattern of cuticle hair so that from the base to the tip of the hair has intermediate structure. All mammals studied, except european badger due to amorphous cellular structure and morphological structures of hair have smooth scale margin. Irregular rippled scale pattern can be observed in all studied species except Bovidae family and wild boar. The pattern of cuticle in the entire hair length of the Bovidae family and wild boar is regularly waved. De Marinis and Asprea (2005) found regularly waved pattern of cuticle in all Cervidae species. But we found them irregularly waved. Eunok et al. (2014) found irregularly waved pattern of cuticle in wild boar. But we found it regularly waved. The pattern of cuticle in european badger is not visible due to morphological structures of hair. All studied mammal species' cuticle features are listed in Table 3.

Table 3. Cuticle features of 18 mammal species from Turkey

\begin{tabular}{l|c|c|c|c}
\hline \multicolumn{1}{c|}{ Species } & Position & Scale margin & Scale pattern & $\begin{array}{c}\text { Distant between } \\
\text { scale margin }\end{array}$ \\
\hline Capra aegagrus & Transversal & Smooth & Regular wave & Distant \\
Gazella subgutturosa & Transversal & Smooth & Regular wave & Distant \\
Rupicapra rupicapra & Transversal & Smooth & Regular wave & Distant \\
Capreolus capreolus & Transversal & Smooth & Irregular wave & Distant \\
Cervus elaphus & Transversal & Smooth & Irregular wave & Distant \\
Dama dama & Transversal & Smooth & Irregular wave & Distant \\
Sus scrofa & Transversal & Smooth & Regular wave & Distant \\
Canis aureus & Transversal & Smooth & Irregular wave & Near \\
Canis lupus & Transversal & Smooth & Irregular wave & Near \\
Vulpes vulpes & Transversal & Smooth & Irregular wave & Near \\
Lynx lynx & Transversal & Smooth & Irregular wave & Near \\
Panthera pardus & Intermediate & Smooth & Irregular wave & Near \\
Martes foina & Transversal & Smooth & Irregular wave & Near \\
Meles meles & Transversal & Not visible & Not visible & Near \\
Lutra lutra & Transversal & Smooth & Irregular wave & Near \\
Ursus arctos & Transversal & Smooth & Irregular wave & Near \\
Lepus europaeus & Transversal & Smooth & Irregular wave & Distant \\
Sciurus anomalus & Transversal & Smooth & Irregular wave & Near \\
\hline
\end{tabular}


We studied the hair structures of eighteen species representing four mammalian orders and nine families including Bovidae, Cervidae, Suidae, Canidae, Felidae, Mustelidae, Ursidae, Leporidae, and Sciuridae. The identification key was developed by using Turkey's 18 mammal species' hairs medulla and cuticle patterns (Fig. 2).

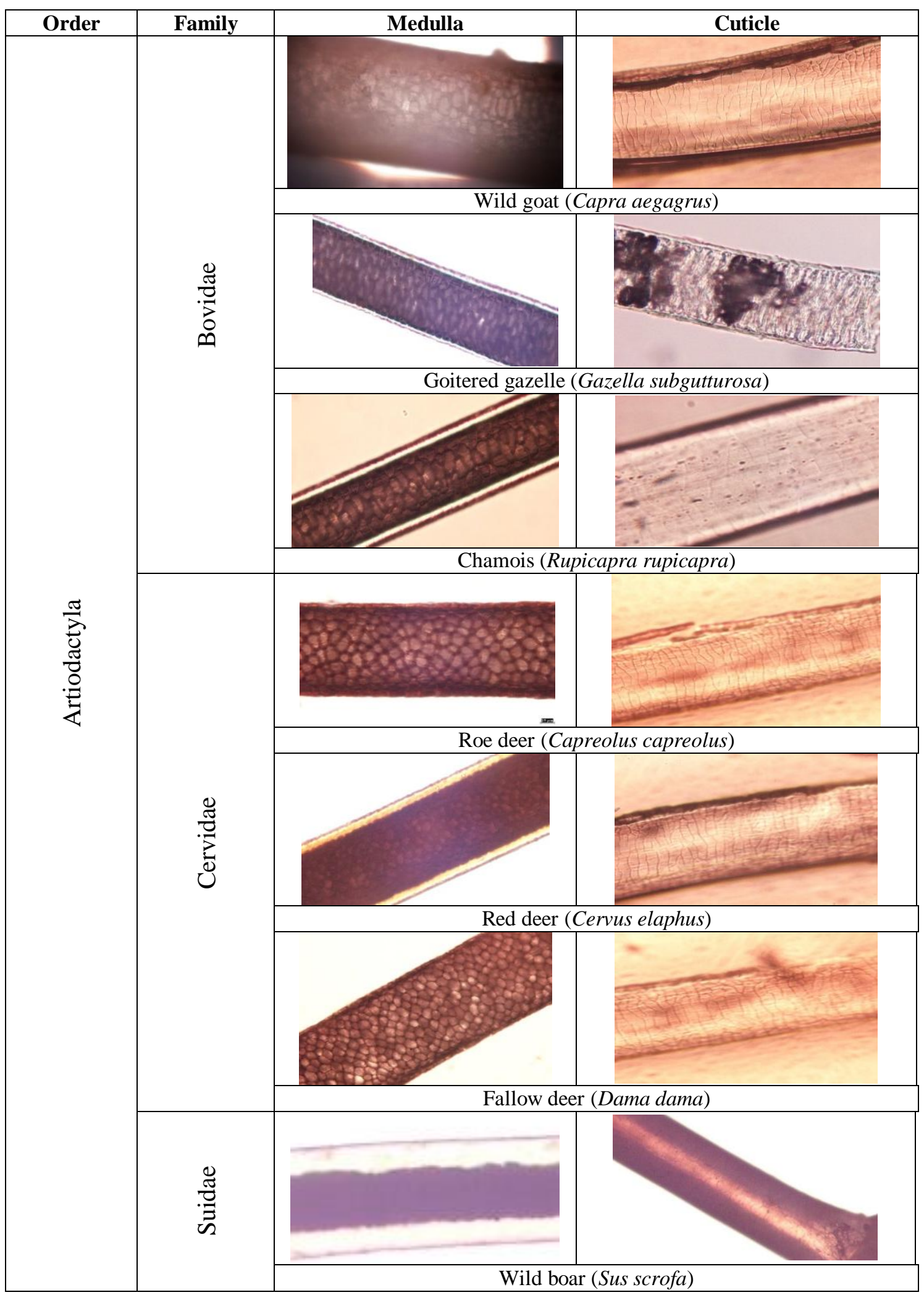




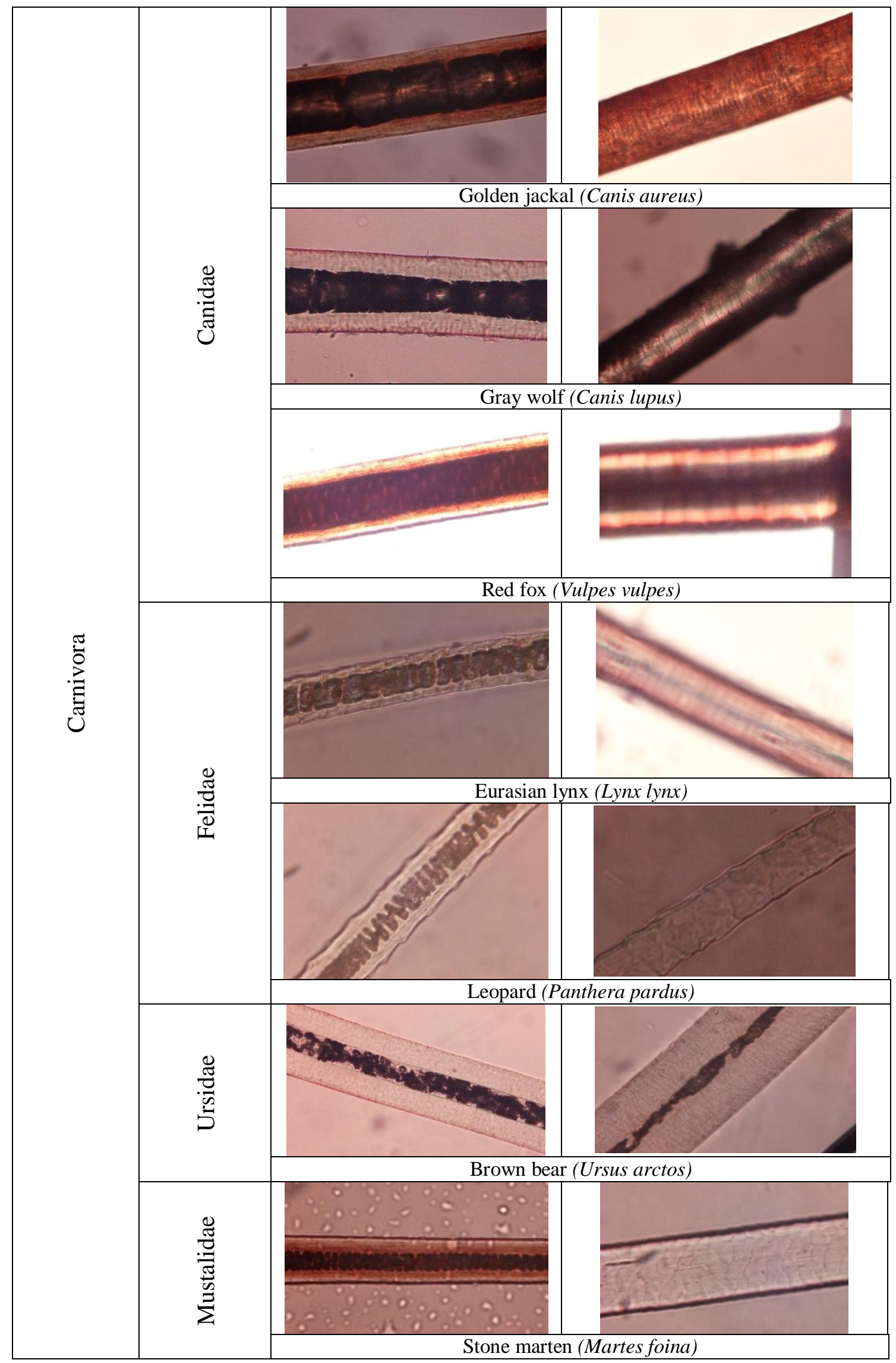

APPLIED ECOLOGY AND ENVIRONMENTAL RESEARCH 16(4):4593-4603.

http://www.aloki.hu • ISSN 15891623 (Print) • ISSN 17850037 (Online)

DOI: http://dx.doi.org/10.15666/aeer/1604_45934603

(c) 2018, ALÖKI Kft., Budapest, Hungary 


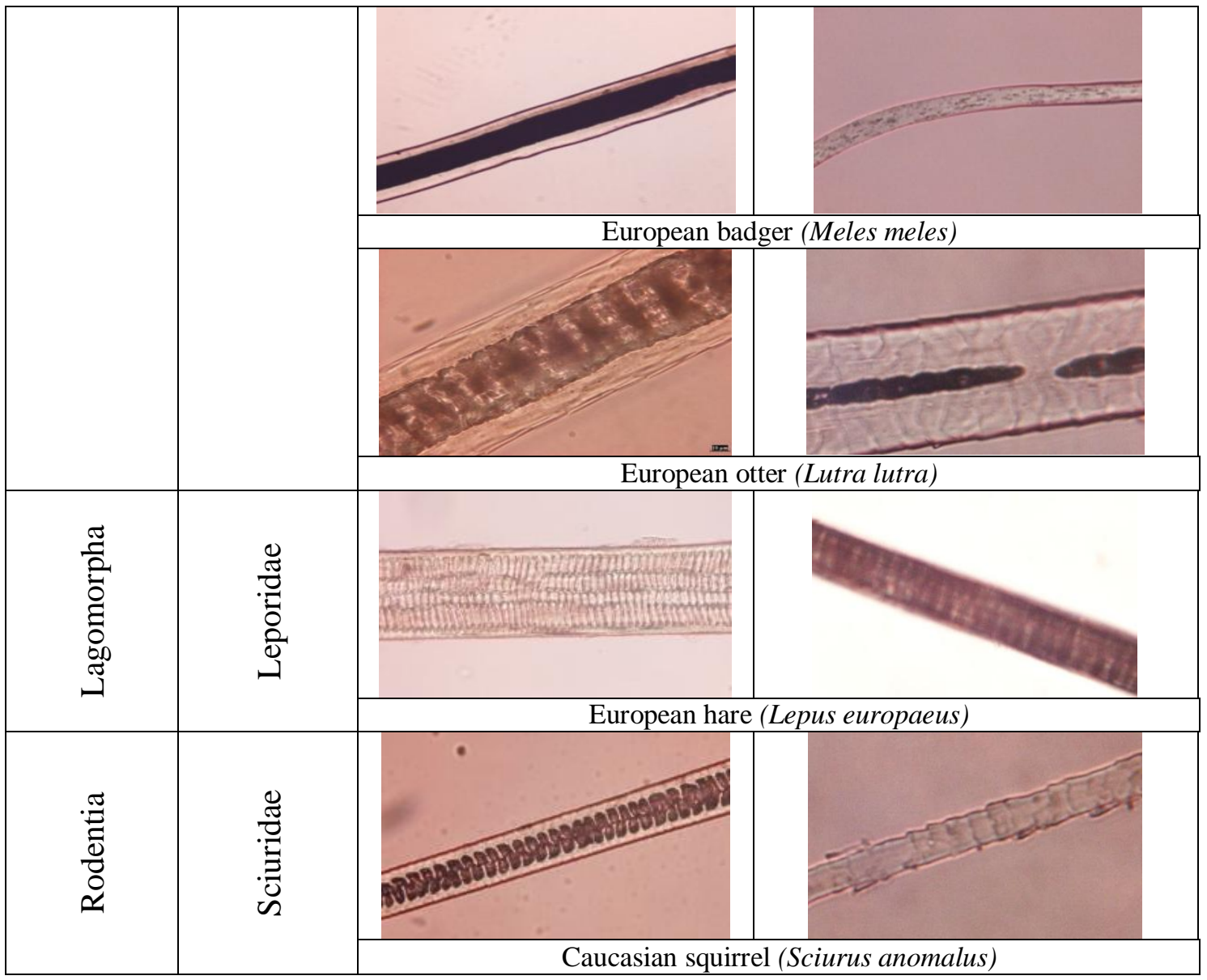

Figure 2. Medulla (left) and Cuticle (right) patterns used in our hair key to identify common mammal species of Turkey

\section{Conclusions}

No studies have constructed identification keys of mammal hair until this time in Turkey. Mammalian species formed by hair identification key occur in major ecosystems of Turkey such as forests, steppe, grasslands, meadows, alpine, high mountains and rivers and experience a wide range of threats. However, ecology, taxonomy, distribution, population sizes and statutes of those species are uncertain due to limited research. With this study, mammalian species can be easily identified by looking at the hair samples in the scats obtained from field studies, and they will be able to get information about their ecologies.

Our hair key allows hair identification based on morphological structures which are clearly recognizable, considering the hair medulla and cuticle. The present research provided a basic guide for wildlife researchers in ecological studies and population management of prey and predators. The techniques employed in this study are relatively simple and can be easily, quickly and economically applied in routine investigations making it suitable for wildlife studies. It is difficult to determine the species from the hair in the scats with the naked eye except for some species which have hard and thick due to variations considerably hair structures between species. Use of hair identification key will be helped to determine the species. 
In Turkey, wildlife studies on mammalian species are still not enough. Therefore, our hair identification key will be helped to provide basic ecological information for sustainable wildlife conservation and management. The present research provided a basic hair identification key for further research in wildlife studies.

\section{REFERENCES}

[1] Anwar, M. B., Nadeem, M. S., Beg, M. A., Kayani, A. R., Muhammad, G. (2012): A Photographic key for the identification of mammalian hairs of prey species in snow leopard (Panthera uncia) habitats of Gilgit - Baltistan Province of Pakistan. - Pakistan J. Zool. 44(3): 737-743.

[2] Boitani, L., Powell, R. A. (2012): Carnivore Ecology and Conservation. A Handbook of Techniques. - Oxford University Press, New York.

[3] Chernova, O. F. (2003): Architectonic and diagnostic significance of hair cortex and medulla. - Biology Bulletin of the Russian Academy of Sciences 30(1): 53-62.

[4] Ciucci, P., Boitani, L., Pelliccioni, E. R., Rocco, M., Guy, I. (1996): A comparison of scat-analysis methods to assess the diet of the wolf Canis lupus. - Wildlife Biology 2: 3748 .

[5] Cornally, A., Lawton, C. (2016): A Guide to the Identification of Irish Mammal Hair. Zoology, School of Natural Sciences, Ryan Institute, National University of Ireland, Galway.

[6] Day, M. G. (1966): Identification of hair and feather remains in the gut and faeces of stoats and weasels. - Journal of Zoology (London) 148: 201-217.

[7] De Marinis, A. M., Agnelli, P. (1993): Guide to the microscope analysis of Italian mammals hairs: Insectivora, Rodentia and Lagomorpha. - Italian Journal of Zoology 60(2): 225-232.

[8] De Marinis, A. M., Asprea, A. (2005): Hair identification key of wild and domestic ungulates from southern Europe. - Wildlife Biology 12(3): 305-320.

[9] Debelica, A., Thies, M. L. (2009): Atlas and Key to the Hair of Terrestrial Texas Mammals. - Special Publications, Number 55: 38. Museum of Texas Tech University, Lubbock.

[10] Debrot, S., Fivaz, G., Mermod, C., Weber, J. M. (1982): Atlas des poils de mammifères d'Europe. - Université de Neuchâtel, Switzerland.

[11] Dziurdzik, B. (1978): Historical structure of the hair in hybrids of European bison and domestic cattle. - Acta Theriologica 23: 277-284.

[12] Eunok, L. E. E., Tae-Young, C. H. O. I., Donggul, W. O. O., Mi-Sook, M. I. N., Shoei, S. H. L. (2014): Species identification key of Korean mammal hair. - The Journal of Veterinary Medical Science 76(5): 667.

[13] Faliu, L., Lignereux, Y., Barrat, I. (1980): Identification des poils des mammifères pyrénéens. - Doñana Acta Vertebrata 7: 125-212.

[14] Gamberg, M., Atkinson, J. L. (1988): Prey hair and bone recovery in ermine scats. Journal of Wildlife Management 52: 657-660.

[15] Gese, E. M. (2001): Monitoring of Terrestrial Carnivore Populations. - In: Gittleman, J. L. et al. (eds.) Carnivore Conservation. Cambridge University Press, Cambridge, UK.

[16] Hausman, L. A. (1920): Structural characteristics of the hair of mammals. - American Naturalist: 496-523.

[17] Homan, J. A., Genoways, H. H. (1978): An analysis of hair structure and its phylogenetic implication among Heteromyid rodents. - Journal of Mammalogy 594: 74-760.

[18] Karanth, K. U., Sunquist, M. E. (1995): Prey selection by tiger, leopard and dhole in tropical forests. - Journal of Animal Ecology 64: 439-450. 
[19] Keller, A. (1978): Détermination des mammifères de la Suisse par leur pelage: I. Talpidae et Soricidae (in French with an English summary: Identification of hairs of Swiss mammals. I. Talpidae and Muridae.) - Revue Suisse de Zoologie 85: 758-761.

[20] Keller, A. (1981): Détermination des mammifères de la Suisse par leur pelage: V. Carnivora, VI. Artiodactyla. (In French with an English summary: Identification of hairs of Swiss mammals. V. Carnivora. VI. Artiodactyla.) - Revue Suisse de Zoologie 88: 803820.

[21] Klare, U., Kamler, J. F., Macdonald, D. W. (2011): A comparison and critique of different scat-analysis methods for determining carnivore diet. - Mammal Review 41(4): 294-312.

[22] Leopold, B. D., Krausman, P. R. (1986): Diets of 3 predators in Big Bend National Park, Texas. - Journal of Wildlife Management 50: 290-295.

[23] Meyer, W., Hülmann, G., Seger, H. (2002): SEM - Atlas of the Hair Cuticle Structure of Central European Mammals. - Verlag M. \& H. Shaper Alfeld, Hannover.

[24] Moyo, T. (2005): The identification of mammalian species through the classification of hair patterns using image pattern recognition. - Afrigraph '06 Proceedings of the 4th International Conference on Computer Graphics, Virtual Reality, Visualisation and Interaction in Africa, Cape Town, South Africa.

[25] Oli, M. K. (1993): A key for the identification of the hair of mammals of a snow leopard (Panthera uncia) habitat in Nepal. - Journal of Zoology 231: 71-93.

[26] Perrin, M. R., Campbell, B. S. (1980): Key to the mammals of the Andries Vosloo Kudu Reserve (Eastern Cape), based on their hair morphology, for use in predator scat analysis. - South African Journal of Wildlife Research 10: 1-14.

[27] Rezaie, A., Kaboli, M., Ashrafi, S., Akbari, H. (2012): Hair Identification Key of Large Mammals in Central Iran: Application for Diet Study in Carnivores. - Department of Environmental Science, Faculty of Natural Resources, University of Tehran, Iran.

[28] Sheppard, S. K., Harwood, J. D. (2005): Advances in molecular ecology: tracking trophic links through predator-prey food webs. - Functional Ecology 19: 751-762.

[29] Symondson, W. O. C. (2002): Molecular identification of prey in predator diets. Molecular Ecology 11: 627-641.

[30] Teerink, B. J. (1991): Hairs of West European Mammals. - Cambridge University Press, Cambridge.

[31] Toth, M. (2002): Identification of Hungarian Mustelidae and other small carnivores using guard hair analysis. - Acta Zoologica Academiae Scientiarum Hungaricae 48(3): 237250 .

[32] Treves, A and Karanth, K. (2003): Human-canrivore conflict and perspectives on carnivore management worldwide. - Conservation Biology 17: 1491-1499.

[33] Tridicio, S. R., Houck, M. M., Kirkbride, K. Paul, Smith, M. E., Yates, B. C. (2014): Morphological identification of animal hairs: Myths and misconceptions, possibilities and pitfalls. - Forensic Science International 238: 101-107.

[34] Wallis, R. L. (1993): A key for the identification of guard hairs of some Ontario mammals. - Canadian Journal of Zoology 71(3): 587-591.

[35] Waters, C., Lawton, C. (2011): Red Squirrel Translocation in Ireland. Irish Wildlife Manuals No. 51. - National Parks and Wildlife Service, Department of the Environment, Heritage and Local Government, Dublin, Ireland. 